\title{
Status Epilepticus Management: A Short Review
}

\author{
Martin Savard MD
}

\section{About the Author}

Martin Savard is a neurologist, specializing in neurocritical care consultation, at Hôpital de l'Enfant-Jésus du CHU, in Quebec City, Quebec. He is also the epilepsy clinic director and the director of the neurology program in Université Laval. Correspondence may be directed to martinsavard17@hotmail.com.

\section{Summary}

Status epilepticus is a common neurological emergency, with high morbidity and mortality, now defined as 5 minutes or more of (1) continuous clinical and/or electrographic seizure activity or (2) recurrent seizure activity without recovery (returning to baseline) between seizures. In observational studies, many disparities exist in management among different medical teams. Here, the author reviews evidence-based medicine data on this management, with emphasis on the use of drugs and electroencephalography. Benzodiazepine (either IV lorazepam or IM midazolam) are the recognized first line of treatment. When a patient is still seizing thereafter, the second line is usually either IV phenytoin or IV valproate, where available. A persisting status epilepticus should then be considered as refractory and managed with anaesthetic drug, keeping in mind that the natural history of that state is to evolve to nonconvulsive status epilepticus, where an emergent EEG is the only way to diagnose that condition with certainty.

\section{Résumé}

Le status epilepticus est une urgence neurologique fréquente, associée à une haute morbidité et mortalité, maintenant définie comme 5 minutes ou plus (1) d'activité ictale continue Clinique et/ou électrographique ou (2) d'activité ictale récurrente sans résolution (retour au niveau de base) entre les crises. Dans des études observationnelles, de nombreuses disparités existent dans sa prise en charge entre les différentes équipes médicales. Nous allons ici réviser les données de la médecine basée sur l'évidence à propos de cette prise en charge, avec une emphase particulière sur les médications et l'utilisation de l'EEG. Les benzodiazépines (soit le lorazépam IV ou le midazolam IM) constituent la première ligne de traitement reconnue. Quand un patient demeure toujours en crise par la suite, la phénytoïne IV ou l'acide valproïque IV (lorsque disponible) sont la seconde ligne de traitement. Un status epilepticus persistant devra par la suite être considéré comme étant réfractaire et traité à l'aide de médication anesthésiante, tout en gardant en tête que l'histoire naturelle de cette condition est d'évoluer en status épilepticus non convulsif, où un EEG d'urgence est la seule façon d'en permettre le diagnostic avec certitude. 
S tatus epilepticus (SE) is one of the more common neurological emergencies, with a $9-21 \%$ mortality associated at hospital discharge. ${ }^{1}$ Among important factors influencing mortality, SE duration is of major importance: mortality goes from $2.7 \%$ to $32 \%$ if SE has, respectively, a length of less than 1 hour or more than 1 hour. ${ }^{2}$ Moreover, the natural history of SE is similar to that for cardiac arrest since a patient with SE will eventually evolve to an "electromechanical dissociation" state, called nonconvulsive SE. At that point, diagnostic delay has been proven to be the major factor influencing mortality, ${ }^{3}$ and only an electroencephalogram (EEG) can be used to accurately diagnose that state. This article therefore concentrates on the major aspects concerning the timely management of SE, its definition, and its appropriate pharmacological management.

The definition of SE used to involve a patient seizing consecutively for 30 minutes, since irreversible lesions appeared in the brain in a monkey model at that point. ${ }^{4}$ New guidelines no longer support that definition. ${ }^{1}$ Since all class 1 studies available considered shorter definitions (from 5 to 10 minutes $^{5-7}$ ) and new data supported the idea that even a few minutes of evolution may have an important impact on SE resolution, ${ }^{7}$ the most recent Neurocritical Care Society (NCS) guidelines ${ }^{1}$ state that SE can be "defined as 5 minutes or more of (i) continuous clinical and/or electrographic seizure activity or (ii) recurrent seizure activity without recovery (returning to baseline) between seizures." This definition also implies that most of the usual tonic-clonic seizures, which have a length of approximately 1 minute and almost always less than 2 minutes, ${ }^{8}$ do not usually necessitate an acute drug treatment. Eventually, $30 \%$ of the SE will evolve to a refractory state (often nonconvulsive), defined has a non-response to a benzodiazepine and a second acceptable drug in appropriate dosing, with an even higher mortality of $23-61 \%{ }^{1}$

Three principal class 1 studies (prospective, multicentric, double-blind, and randomized) influence the way we manage SE pharmacologically. The two first are paramedic studies, and the last one is an emergency room (ER) study.

The first to consider here is the San Francisco Emergency Medical Service study. ${ }^{6}$ Paramedics there were treating adults with 5 minutes or more of consecutive clinical seizure activity with intravenous (IV) diazepam $5 \mathrm{mg}$, IV lorazepam $2 \mathrm{mg}$, or placebo. Placebo was considered ethical in this case since San Francisco paramedics had not been treating SE with IV drugs previously and there was some concern that IV benzodiazepine in that setting may cause respiratory distress and morbidity. The primary outcome was the presence or not of a persisting SE at arrival in the emergency department. A total of 205 patients were enrolled in that study. A significant statistical difference favoured the use of lorazepam compared with placebo $(40.9 \%$ versus $78.9 \%, p=$
.001), whereas a non-statistically significant difference was found when compared with diazepam (57.4\%). Interestingly, the group having more respiratory complications was the placebo group (22.5\%, versus $10.6 \%$ for lorazepam and $10.3 \%$ for diazepam; $p=.08$ ), supporting the notion that seizing is bad for airway protection.

The second is the most recent one, the Rampart study, ${ }^{7}$ which had the objective to prove that intramuscular (IM) midazolam (5-10 mg) is not inferior to IV lorazepam (2-4 mg). This objective was motivated by the point that an IV access may be tricky to find in a seizing patient, and moreover because the IV lorazepam solution has to be refrigerated. The study finally demonstrated a superiority of IM midazolam, with $73.4 \%$ of patients being seizure free when entering the emergency room compared with $63.4 \%$ of those treated with IV lorazepam $(p<.001)$. Both drugs were considered safe. It has been suggested that the difference between the two groups was secondary to the fact that it took less time to use the IM treatment (1.2 minutes) than the IV treatment (4.8 minutes).

The third study is known as the Veteran study. ${ }^{5}$ Four different blinded treatments were evaluated in the emergency room for patients seizing for at least 10 minutes. The only statistical difference was between IV lorazepam (64.9\% efficacy) and IV phenytoin $(43.6 \%$ efficacy), with intermediary results for phenobarbital and a phenytoin-plus-diazepam combination. The lorazepam dosage used in this study was $0.1 \mathrm{mg} / \mathrm{kg}$. A very interesting point is that the investigators also blindly evaluated the second- and third-line efficacy of these drugs, with a collective result of $7.3 \%$ and $2.0 \%$, respectively. These data are the basis of the refractory SE definition discussed above.

In parallel with treatment, a diagnosis workup has to be made. The NCS guidelines ${ }^{1}$ suggest the following: (1) vital sign monitoring; (2) finger-stick glucose; (3) brain computed tomography (CT) scan (for most cases); (4) basic blood tests (including calcium, magnesium, and anticonvulsant levels); and (5) continuous EEG monitoring. Based on the clinical presentation, a lumbar puncture, magnetic resonance imaging (MRI), and a toxicology screen can be considered. EEG monitoring remains the most difficult recommendation to follow, but it is motivated by the possibility of a nonconvulsive seizure evolution, which is present in $14 \%$ of controlled convulsive SE. ${ }^{9}$ The " 15 minute rule" can be used here; this means that even if a patient is still comatose, there must be a clinical improvement within 15 minutes of the last seizure. If not, if available, an emergent EEG must be considered to rule out nonconvulsive SE; if this is unavailable, an intubation associated with an anaesthetic agent (preferably propofol) should be instituted and then stopped after 12-24 hours of treatment. If the patient does not improve 


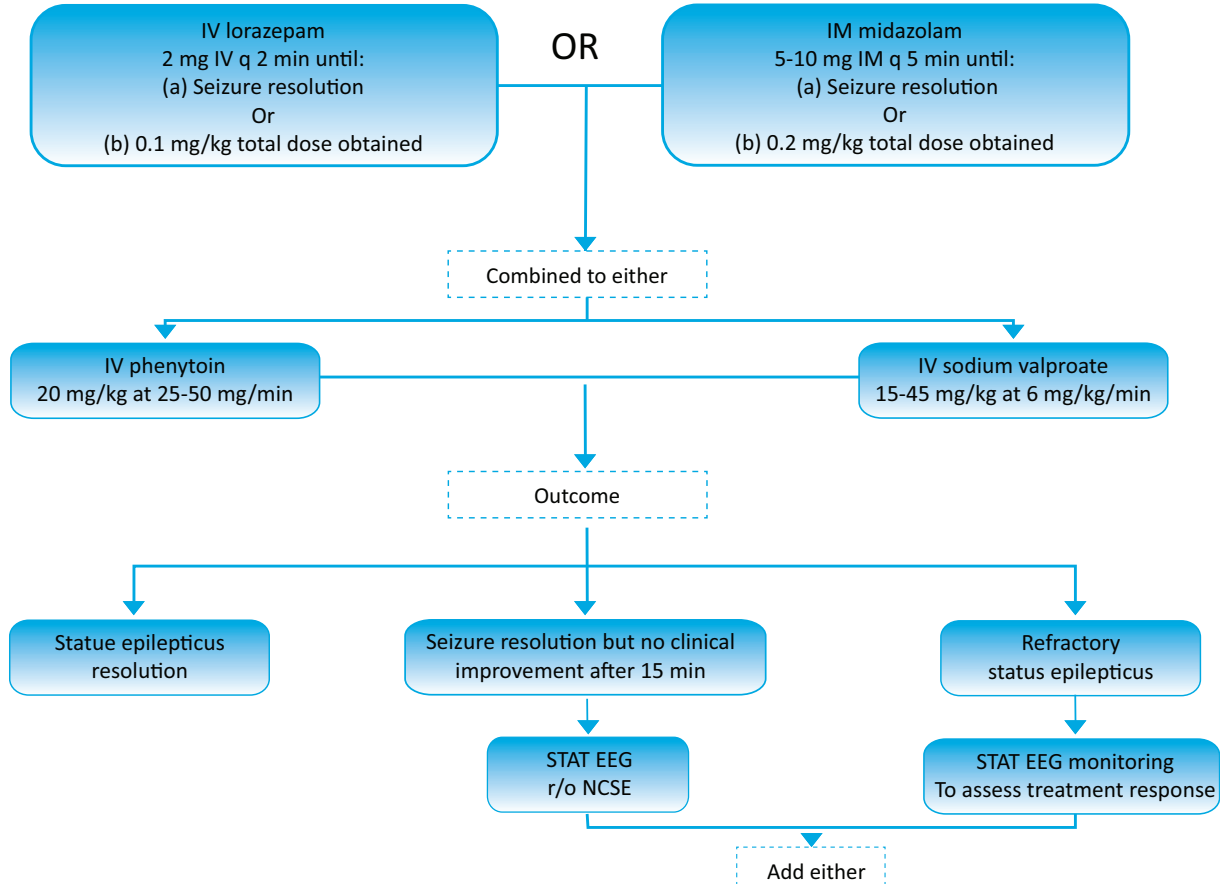

Figure 1. Suggested algorithm in treating status epilepticus (see text for details). $\mathrm{EEG}=$ electroencephalogram; NCSE = nonconvulsive status epilepticus; $r / 0=$

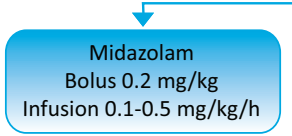
rule out.

in the 15-30 minutes after the end of the propofol perfusion, he or she must be transferred to a hospital where EEG (preferably continuous EEG) is available. If needed, supportive treatment must also include ventilation assistance, pressors, and fluid resuscitation (especially keeping in mind the acute tubular necrosis risk secondary to rhabdomyolysis). Hyperthermia should be treated.

When benzodiazepines are not working, IV phenytoin or valproic acid must be considered; but, as discussed above, most patients will remain refractory at this point. Of interest, two prospective comparative studies ${ }^{10,11}$ have since compared IV phenytoin and valproate, favouring valproate in each case. However, valproate is still underused and therefore has low general clinical experience. As a consequence, IV phenytoin and valproate are usually considered equal as second line choices.

IV anaesthetics are to be considered thereafter, particularly midazolam (bolus $0.2 \mathrm{mg} / \mathrm{kg}$, perfusion $0.1-2.0 \mathrm{mg} / \mathrm{kg} / \mathrm{h}$ ) or propofol (bolus 2-5 mg/kg, perfusion $1.0-4.5 \mathrm{mg} / \mathrm{kg} / \mathrm{h}$; avoid in children and for perfusions lasting $>48$ hours because of the risk of deadly propofol infusion syndrome ${ }^{12}$ ). If the patient is still seizing during perfusion with midazolam or propofol, additional options are barbiturate, isoflurane, or ketamine. Finally, anaesthetic treatment has to be stopped every 24-48 hours. Other treatments may be tried in parallel at this point; there is some anecdotal evidence for the use of topiramate, levetiracetam, magnesium, or lacosamide, or even surgery and electroconvulsive therapy. ${ }^{13}$ Since many good outcomes have been reported, even when a patient has been in SE for weeks, if the prognosis is otherwise not bad (e.g., the SE is not caused by a malignant tumour), the key point is to be very patient.

In conclusion, $\mathrm{SE}$ is a neurological emergency in which the decisions taken during the first few hours have a great impact on the outcome, and where evidence-based medicine can guide our initial decisions. A suggested treatment algorithm is provided in Figure 1 . Refractory SE is a less well-known entity, but remains a treatable state. However, with no evidence-based guidelines available at this time, its management is more art than science.

\section{References}

1. Brophy GM, Bell R, Claassen J, et al. Guidelines for the evaluation and management of status epilepticus. Neurocrit Care 2012;17:3-23.

2. Towne AR, Pellock JM, Bo D, et al. Determinants of mortality in status epilepticus. Epilepsia 1994;35:27-34.

3. Young GB, Jordan KG, Doig GS. An assessment of nonconvulsive seizures in the intensive care unit using continuous EEG monitoring: an investigation of variables associated with mortality. Neurology 1996;47:839.

4. Meldrum BS, Brierley JB. Prolonged epileptic seizures in primates. Ischemic cell change and its relation to ictal physiological events. Arch Neurol 1973;28:10-7.

5. Treiman DM, Meyers PD, Walton NY, et al. A comparison of four treatments for generalized convulsive statust epilepticus. N Engl J Med 1998;339:792-8.

6. Alldredge BK, Gelb AM, Isaacs SM, et al. A comparison of lorazepam, diazepam, and placebo for the treatment of out-of-hospital status epilepticus. N Engl J Med 2001;345:631-7.

7. Silbergleit R, Durkalski V, Loweinstein D, et al. Intramuscular versus intravenous therapy for prehospital status epilepticus. N Engl J Med 2012;366:591-600.

8. Theodore WH, Porter RJ, Albert P, et al. The secondarily generalized tonicclonic seizure: a videotape analysis. Neurology 1994;44:1403-7.

9. DeLorenzo RJ, Waterhouse EJ, Towne AR, et al. Persistent non-convulsive status epilepticus after the control of convulsive status epilepticus. Epilepsia 1998;39:833-40.

10. Misra UK, Kalita J, Patel R. Sodium valproate vs phenytoin in status epilepticus: a pilot study. Neurology 2006;67:340-2.

11. Agarwal P, Kumar N, Chandra R, et al. Randomized study of intravenous valproate and phenytoin in status epilepticus. Seizure 2007;16:527-32.

12. Fodale V, La Monaca E. Propofol infusion syndrome : an overview of a perplexing disease. Drug Safety 2008;31:293-303.

13. Hunter G, Young GB. Status epilepticus: a review, with emphasis on refractory cases. Can J Neurol Sci 2012;39:157-69. 